\title{
Relationship between vessel porosity and leaf emergence pattern in ring- and diffuse-porous deciduous trees in a temperate hardwood forest
}

\author{
AUTHOR(S): \\ Takahashi, Sayaka; Okada, Naoki; Nobuchi, \\ Tadashi
}

\section{CITATION:}

Takahashi, Sayaka ...[et al]. Relationship between vessel porosity and leaf emergence pattern in ring- and diffuse-porous deciduous trees in a temperate hardwood forest. Botany 2015, 93(1): 31-39

\section{ISSUE DATE:}

2015-01

URL:

http://hdl.handle.net/2433/192940

\section{RIGHT:}

(c) Copyright 2014 - Canadian Science Publishing; この論文は出版社版 でありません。引用の際には出版社版をご確認ご利用ください。; This is not the published version. Please cite only the published version. 


\section{Relationship between vessel porosity and leaf emergence pattern in ring- and} diffuse-porous deciduous trees in a temperate hardwood forest

Sayaka Takahashi, Naoki Okada, and Tadashi Nobuchi

Sayaka Takahashi ${ }^{1}$, Naoki Okada, and Tadashi Nobuchi: Division of Forest and Biomaterials

Science, Graduate School of Agriculture, Kyoto University, Oiwake-cho Kitashirakawa Sakyo-ku Kyoto, 606-8502, Japan

Sayaka Takahashi E-mail: sayakane@kais.kyoto-u.ac.jp,

Naoki Okada E-mail: okad@kais.kyoto-u.ac.jp

Tadashi Nobuchi E-mail: tmnobuchi.tm@nike.eonet.ne.jp

${ }^{1}$ Corresponding author

Telephone: +81-75-753-6096

Fax: +81-75-753-6098

Takahashi et al. 1 


\begin{abstract}
To elucidate the functional relationship between intra-annual variations in vessel diameter and leaf emergence pattern of ring-porous and diffuse-porous deciduous trees in temperate forests, we determined the temporal relationships between leaf phenology and vessel formation. Cylindrical stem cores were periodically collected from each of five ring- and diffuse-porous species, and the leaf and vessel formation were observed simultaneously. In the ring-porous species, vessel formation began within 2 weeks of leaf appearance, and most wide vessels were formed within 2 weeks of full leaf expansion. More of the trees with intermediate-type formed medium-sized vessels or sparse wide vessels than trees with flush-type leaf emergence, especially between full leaf expansion and the end of shoot elongation. Narrow vessel formation began 2-8 weeks after full leaf expansion in all specimens. The transition between the pore- and non-pore zones was abrupt in the flush-type species and gradual in the intermediate-type species. In contrast, diffuse-porous species formed vessels $0-8$ weeks after full leaf expansion. Our findings suggest that ring-porous species form leaves and vessels synchronously to accommodate water-transport requirements, whereas diffuse-porous species form these tissues asynchronously; thus, unlike the latter type, the former species change vessel diameters according to leaf formation.
\end{abstract}

Keywords: vessel diameter, leaf phenology, vessel arrangement, seasonal change, functional ecology

Takahashi et al. 2 


\section{Introduction}

Vessel porosity, which is defined as the changes in diameter across an annual ring, and radial distribution of vessels in annual rings are likely associated with the tree's seasonal water use. This presumption then leads to the hypothesis that vessel formation is associated with the leaf emergence pattern of each species. This study aimed to test this hypothesis by using wood anatomical and leaf phenological analyses on deciduous broad-leaved tree species.

The association between leaf and vessel formation has been discussed by various researchers (e.g., Ladefoged 1952; Lechowicz 1984; Begum et al. 2013; Panchen et al. 2014). In temperate trees, woody tissue is characterized by one of three types of porosity (Wheeler et al. 1989). Unlike Wheeler et al. (1989) who studied the anatomical porosity phase, we studied the phenological phase and found that ring-porous species form wider vessels in the early annual ring and then form narrower vessels; diffuse-porous species form vessels with similar diameter across the annual ring; and semi-ring-porous species are intermediate in character. Leaf emergence pattern has been systematically investigated (Kikuzawa 1983). In this study, we attempted to elucidate the relationships between intra-annual changes in vessel diameter and leaf emergence pattern in ring-porous and diffuse-porous species by determining the relationships between leaf phenology and vessel formation.

Previous studies have revealed that the timing of vessel formation relative to leaf expansion of ring-porous species is different from that of diffuse-porous species in the early stage of annual ring formation (Suzuki et al. 1996; Takahashi et al. 2013). The first-formed stem vessels of ring-porous species develop new rings adjacent to the annual ring border and mature around the time of leaf expansion (Suzuki et al. 1996). Additionally, vessel maturation of the species occurs at the time of leaf budding (Zasada and Zahner 1969; Suzuki et al. 2000), and vessel lignification occurs within a short time of leaf appearance and by the time of full leaf expansion (Takahashi et al. 2013). In contrast, vessels of diffuse-porous species mature more than a month after the onset of leaf expansion (Suzuki et al. 1996) or around the time of full leaf expansion (Suzuki et al. 2000), and vessel lignification occurs at least 4 weeks after leaf appearance and from 0 to 8 weeks after full leaf expansion (Takahashi et al. 2013). Wide vessels of ring-porous species are known to transport water mostly during the year in which they are formed (Greenidge 1955; Chaney and 
Kozlowski 1977; Ellmore and Ewers 1986; Utsumi et al. 1999; Umebayashi et al. 2008). In contrast, vessels in several rings adjacent to the cambium retain their water transportation ability in diffuse-porous species (Greenidge 1955; Chaney and Kozlowski 1977; Utsumi et al. 1998; Umebayashi et al. 2008). Thus, ring-porous species produce single-year leaves and most functional vessels in a short, intensive period, whereas the production of single-year leaves and multiple-year vessels is less intensive in diffuse-porous species (Takahashi et al. 2013). There are prominent differences in the wood-formation process between ring- and diffuse-porous species (Suzuki et al. 1996; Takahashi et al. 2013), but such comparisons have generally been restricted to the early stage of annual ring formation.

In the later stage of annual ring formation, small vessels of the first-formed latewood in ring-porous species are completed by full leaf expansion (Suzuki et al. 2000), whereas later-formed earlywood vessels are completed several weeks after full leaf expansion (Zasada and Zahner 1969). The relationship between leaf phenology and vessel formation in the later stage of wood formation remains unclear. We tested the hypothesis that vessel porosity and vessel density in a ring are associated with leaf emergence pattern in deciduous broad-leaved trees.

To elucidate the functional linkage between intra-annual changes in vessel diameter and leaf emergence pattern, we determined the temporal relationships between vessel formation and leaf phenology throughout the early stage to the later stage of annual ring formation in ring-porous trees and compared them with those in diffuse-porous trees in temperate deciduous forests where both species grow in the same forest stand. According to the theoretical relative conductance predicted by the Hagen-Poiseuille law, flow rate is proportional to the fourth power of the capillary radius (Ellmore and Ewers 1986; Tyree and Zimmermann 2002). In this study, vessels were categorized as the widest vessels, which had the highest water transport capacity; medium-sized vessels, which had 16- to 256-fold less conductivity than the widest vessels; and narrow vessels, which had $\geq 256$-fold less conductivity than the widest vessels. Each leaf phenological stage for the entire tree was investigated, unlike in previous studies that focused on shoot-level phenology (e.g., Kikuzawa 1983). 


\section{Materials and methods}

\section{Study site and sample trees}

The study was conducted at the Kyoto University Forest in Ashiu $\left(35^{\circ} 18^{\prime} \mathrm{N}, 135^{\circ} 4^{\prime} \mathrm{E}\right)$, Kyoto Prefecture, central Japan. The dominant species in this cool temperate forest are Fagus crenata Blume and Quercus mongolica Fisch. Ex Ledeb. var. grosseserrata (Blume) Rehder \& E.H.Wilson. The mean annual temperature for a 30 year period from 1971 to 2000 at the Ashiu Forest Research Station at $356 \mathrm{~m}$ a.s.1. was $11.7^{\circ} \mathrm{C}$ with mean minimum and maximum temperatures of -0.2 and $24.2^{\circ} \mathrm{C}$, respectively. The mean annual precipitation from 1971 to 2000 was 2,353 mm (Forest Research Station of Graduate School of Agriculture, Kyoto University, 2002). The elevation of the study site is $650-670 \mathrm{~m}$ a.s.l. The study area included $20 \mathrm{~m}$ on either side of a $1 \mathrm{~km}$ length of path in a flat-bottomed, south-facing valley. All sample trees were under similar weather conditions.

Sample trees (Table 1, Supplementary Fig. S1) were selected in 2004 from canopy trees of four ring-porous species (Castanea crenata Siebold \& Zucc., Fraxinus mandshurica Rupr., $Q$. mongolica var. grosseserrata, and Zelkova serrata (Thunb.) Makino) and five diffuse-porous species (Aesculus turbinata Blume, Betula grossa Siebold \& Zucc., Cercidiphyllum japonicum Siebold \& Zucc., Fagus crenata, and Pterocarya rhoifolia Siebold \& Zucc. In 2005, we added another ring-porous species, Hovenia tomentella (Makino) Nakai. Study trees were selected from individuals with diameter at breast height of $18-74 \mathrm{~cm}$, height of 9-31 m, and relatively straight stems. All species occur naturally in Ashiu with the exception of Fraxinus mandshurica, which is non-native and was planted, and all Z. serrata trees investigated in this study were planted.

\section{Sampling}

Cylindrical wood core samples (diameter, $7 \mathrm{~mm}$; length, $20 \mathrm{~mm}$ ) were collected in 2004 and 2005 from five trees of each species, at breast height (1.3 $\pm 0.2 \mathrm{~m}$ above the ground), using an increment borer (Mattson, Mora, Sweden). Stem cores were fixed with 3\% aqueous glutaraldehyde shortly after sampling. In 2004, samples were collected biweekly between 22 April and 1 July, and monthly between 22 July and 16 November, resulting in a total of 11 
sampling events. In 2005, samples were collected on 19 April and biweekly between 28 April and 21 July, resulting in eight sampling events.

\section{Assessment of vessel formation}

Vessel development begins with cambial cell division, followed by enlargement of vessel elements, deposition and lignification of the secondary cell wall, and disintegration of the end walls (Imagawa and Ishida 1972; Wakuta et al. 1973; Fukushima et al. 2003). We assessed lignification of vessels by red staining (Sass 1951; Imagawa and Ishida 1972; Takahashi et al. 2008). Transverse sections with a thickness of $20-30 \mu \mathrm{m}$ were cut using a sliding microtome (Yamato TU-213; Saitama, Japan). The sections were double-stained with 1\% safranin O, which stains lignin red, and $1 \%$ fast green FCF, which stains cellulose blue but only in the absence of lignin, for light microscopy examination (Olympus BX-50-32; Tokyo, Japan; Sass 1951). When double-staining results were ambiguous, a phloroglucinol- hydrochloric acid reaction was used (Takahashi et al. 2008). The date of lignification was recorded as the first date on which lignification of at least one enlarged vessel was observed.

In ring-porous species, three size classes of vessels (Ewers and Fisher 1989) were measured on the basis of the maximum radial diameter $\left(r d_{\max }\right)$ of the first-formed vessels, which formed first in the current growth ring, often adjacent to the annual ring border (Fig. 1). Wide vessels are defined as $>0.5 r d_{\max }$, medium-sized vessels as $\leq 0.5 r d_{\max }$ and $>0.25 r d_{\max }$, and narrow vessels as $\leq 0.25$

$r d_{\text {max }}$. When there was a mixture of different-sized vessels, vessel size was defined according to the wider vessels from the perspective of fluid conductance. Sparse wide vessels are those that are present in lower density than first-formed vessels or equal half the number of first-formed vessels. Vessel size and density were measured tangentially using 2-3 mm long transverse sections.

\section{Observation of leaf phenology}

In 2004 and 2005, leaves from each tree sampled were examined with binoculars (Nikon 8X30 $8.8^{\circ} \mathrm{WF}$; Tokyo, Japan) at ca. 2 week intervals and photographed in situ. We distinguished between flush leaves and successive leaves (Kikuzawa 1983; Miyazawa and Kikuzawa 2004). Flush leaves (i.e., early leaves) appear almost simultaneously in a short period immediately after 
budbreak in early spring, whereas successive leaves (i.e., late leaves) appear gradually over a longer period.

The type of leaf emergence pattern, i.e., flush, succeeding, or intermediate was determined for each species by seasonal observations and using the criterion defined by Kikuzawa (1983). We observed only flush and intermediate emergence patterns (Table 1). Species with flush-type emergence had flush leaves only, whereas species with intermediate-type emergence had both flush and successive leaves.

The following phenological parameters were observed: leaf appearance was defined as the time at which the lamina separated from the shoot axis (Kikuzawa 1983), and full leaf expansion was defined as the time at which leaf area was judged to have increased (Suzuki et al. 2000). The following terms refer to the whole-tree level in this paper, unless indicated otherwise. "The beginning of leaf appearance" indicates that at least one flush leaf had appeared; "completion of leaf appearance" indicates almost all flush leaves had appeared; "full leaf expansion" indicates most of the flush leaves had fully expanded (also used when successive leaves of $H$. tomentella had fully expanded after the end of elongation); and "the end of elongation" indicates the point at which new successive leaves stopped appearing. At the end of elongation, species with sympodial branching dropped their shoot-tips, and species with monopodial branching produced winter buds, but no new leaves appeared. The dates of each phenological stage for individual trees were recorded as the first date on which each stage was observed. Leaf appearance stages clearly differed from the full leaf expansion stage in the intensity of greenness.

\section{Results}

Temporal relationships between leaf phenology and vessel formation in ring-porous species

The timing of vessel lignification and leaf phenology in the ring-porous species is shown in Figs. 2A-2J. 


\section{Timing of wide vessel lignification}

At least one wide vessel had lignified between 4 weeks before and 2 weeks after the completion of leaf appearance in ring-porous species (Fig. 2B). In species with flush-type leaf emergence patterns, at least one wide vessel had lignified between 0 and 2 weeks after the beginning of leaf appearance (Fig. 2A), and most wide vessels were lignified 0-2 weeks before full leaf expansion (Fig. 2D). In species with intermediate-type leaf emergence patterns, at least one wide vessel had lignified between 0 and 2 weeks before the beginning of leaf appearance (Fig. 2A), and lignification of most wide vessels was observed between 4 weeks before and 2 weeks after full leaf expansion (Fig. 2D). Lignification of sparse wide vessels was observed 2 weeks before full leaf expansion in the trees that showed lignification of most wide vessels 4 weeks before full leaf expansion (Fig. 2E). Therefore, independent of wide vessel density, wide vessels lignified between 2 weeks before and 2 weeks after full leaf expansion. Lignification occurred later in H. tomentella; specimens showed lignification of at least one wide vessel $0-2$ weeks before full leaf expansion, although lignification was observed in other species 2-6 weeks before full leaf expansion (Fig. 2C). Sparse wide vessels had become lignified close to the time of full leaf expansion ( \pm 2 weeks), although these vessels formed 2-6 weeks after full leaf expansion when second leaves appeared in Z. serrata (Fig. 2E).

\section{Timing of medium-sized vessel lignification}

Among species with flush-type leaf emergence patterns, medium-sized vessels formed in five of nine Q. mongolica var. grosseserrata specimens and did not form in Z. serrata in 2004 (Fig. 2F). In contrast, among species with intermediate-type leaf emergence patterns, all Castanea crenata and $H$. tomentella, and four of ten Fraxinus mandshurica specimens formed medium-sized vessels (Fig. 2F). Four other F. mandshurica specimens formed sparse wide vessels rather than medium-sized vessels.

Lignification of at least one medium-sized vessel occurred 0-4 weeks after full leaf expansion in $Q$. mongolica var. grosseserrata, and $0-4,0-2$, and 4 weeks after full leaf expansion in Castanea crenata, Fraxinus mandshurica, and $H$. tomentella, respectively (Fig. 2F). Lignification of most medium-sized vessels occurred >2-4 weeks before, $0-4$ weeks before, and 
2-4 weeks after the end of elongation or 0-2 weeks after full leaf expansion of successive leaves in Castanea crenata, Fraxinus mandshurica, and H. tomentella, respectively (Figs. 2G, 2H). Thus, intermediate-type species had a stronger tendency to form medium-sized vessels or sparse wide vessels than flush-type species, and lignification occurred the latest in $H$. tomentella (Figs. 2E, 2F, $2 \mathrm{G})$.

\section{Timing of narrow vessel lignification}

Narrow vessels formed after the appearance of wide or medium-sized vessels. At least one narrow vessel had lignified between 2 and 8 weeks after full leaf expansion in all specimens (Fig. 2I). Relative to the end of elongation, lignification of narrow vessels occurred at or before this stage in Castanea crenata, within \pm 2 weeks of this stage in Fraxinus mandshurica, and $\geq 4$ weeks after this stage in $H$. tomentella (Fig. 2J).

\section{Temporal relationships between leaf phenology and vessel formation in diffuse-porous} species

\section{Timing of lignification of the first-formed vessel}

At least one of the first-formed vessels lignified 0-8 and 0-6 weeks after full leaf expansion in species with flush- and intermediate-type leaf emergence patterns, respectively, or 9 weeks before to 2 weeks after the end of elongation (Figs. 3A, 3B). No new vessels were observed in one Cercidiphyllum japonicum tree in 2004 and 2005 or in one Fagus crenata tree in 2004 (Table 1).

\section{Relationship between leaf emergence pattern and vessel arrangement}

Ring- and diffuse-porous species have both flush- and intermediate-type leaf emergence patterns (Table 2). The type of porosity and leaf emergence pattern of each species investigated in this study are shown in Table 1; microphotographs of vessel arrangement in each species are shown in Figure 1. There were two groups of ring-porous species. Quercus mongolica var. grosseserrata and $Z$. serrata formed wide vessels first in the current growth ring and then formed narrow vessels and few medium-sized vessels, whereas Castanea crenata, Fraxinus mandshurica, and $H$. tomentella formed wide vessels first and then formed one or more rows of medium-sized 
vessels (or sparse wide vessels) and narrow vessels (Figs. 1, 2E, 2F). The transition between the pore- and non-pore zones in the former group was abrupt and that in the latter group was gradual. There was no apparent relationship between leaf emergence pattern and vessel arrangement in diffuse-porous species (Table 1, Fig. 1).

\section{Discussion}

\section{Relationship between leaf phenology and vessel formation}

\section{Comparison of ring-porous and diffuse-porous species}

In ring-porous species, secondary wall deposition of the first vessel elements is completed from 1 week before to 3 weeks after leaf expansion (Suzuki et al. 1996), and maturation occurs within 1 week of leaf budding (Suzuki et al. 2000). This timing coincides with or occurs just before bud opening (Lodewick 1928; Zasada and Zahner 1969) and after the onset of leaf unfolding (Atkinson and Denne 1988; Fonti et al. 2007). The timing of first vessel maturation relative to bud break is species-specific (Sass-Klaassen et al. 2011). In the present study, at least one wide vessel was lignified between 2 weeks before the beginning of leaf appearance and 2 weeks after the completion of leaf appearance in ring-porous species (Figs. 2A, 2B). Relative to the beginning of leaf appearance, at least one wide vessel was lignified between 0 and 2 weeks after in flush-type species and between 0 and 2 weeks before in intermediate-type species (Fig. 2A). Thus, at least one wide vessel would be formed within a short time of leaf appearance, and the timing, which is before or after leaf appearance, is considered to be species-specific. Moreover, lignification of most wide vessels in ring-porous species was observed 4 weeks before to 2 weeks after full leaf expansion (Fig. 2D). Lignification of sparse wide vessels was observed 2 weeks before full leaf expansion in the trees that showed lignification of most wide vessels 4 weeks before full leaf expansion (Fig. 2E). Therefore, independent of wide vessel density, wide vessels were lignified between 2 weeks before and 2 weeks after full leaf expansion. Therefore, most wide vessels would be formed within a short time of full leaf expansion.

A rapid decline in vessel diameter at the end of pore-zone formation coincided with the cessation of shoot elongation (Denne, 1976); therefore, the pore-non-pore transition in 
ring-porous species occurred when shoot extension ceased (Digby and Wareing 1966). Lignification of medium-sized vessels occurred 0-2 weeks after full leaf expansion in flush-type species, except for Z. serrata, which formed wider vessels when second leaves appeared, and one Q. mongolica var. grosseserrata tree, which had Japanese oak wilt disease (Fig. 2F). In intermediate-type species, medium-sized vessels were lignified between 0 and 4 weeks after full leaf expansion (Fig. 2F) and before the end of elongation (Fig. 2G), or around full leaf expansion of successive leaves (Fig. 2H). Thus, the decline in vessel diameter is considered to coincide with the cessation of shoot extension - from full leaf expansion to the end of elongation or full leaf expansion of successive leaves.

These findings suggest that ring-porous species produce leaves and most hydraulically functional vessels intensively over a short time in the early stage of annual ring formation; after early growth, these species synchronously produce subsequent leaves and vessels. This suggests that ring-porous species change vessel diameters according to leaf formation.

In contrast, in diffuse-porous species, at least one of the first-formed vessels lignified 0-8 weeks after full leaf expansion in flush-type species and slightly sooner in intermediate-type species (Fig. 3A), which was the same as or later than that reported by Lodewick (1928) and Suzuki et al. (2000). Lignification occurred before the end of elongation in most intermediate-type species (Fig. 3B). Thus, diffuse-porous species are considered to begin forming the first vessels after full leaf expansion or before the end of elongation in intermediate-type species. Further, diffuse-porous species might form no new vessels in at least one direction; a few of our samples showed no new vessels.

These findings suggest that diffuse-porous species produce leaves and vessels less intensively in the early stage of annual-ring formation and produce subsequent leaves and vessels asynchronously after the early growth. This suggests that the time of formation of vessels is not closely related to that of leaves in diffuse-porous species.

Phylogenetic analysis revealed that ring-porous Castanea crenata and Q. mongolica var. grosseserrata showed synchronous formation of leaves and vessels, whereas diffuse-porous Fagus crenata showed asynchronous formation of these elements among Fagaceae (Supplementary Fig. S1). Although phylogenetically distant, ring-porous species showed the 
same tendency of leaf and vessel formation (e.g., Castanea crenata and Fraxinus mandshurica; Supplementary Fig. S1) and, although phylogenetically distant, diffuse-porous species showed the same tendency of leaf and vessel formation (e.g., Fagus crenata and Cercidiphyllum japonicum; Supplementary Fig. S1).

\section{Timing of narrow vessel formation in ring-porous species}

The first-formed narrow vessels in ring-porous species are thought to be completed around the time of full leaf expansion (Suzuki et al. 2000), coinciding with final leaf expansion (Lodewick 1928). However, the non-pore zone was reported to form several weeks after maturation of foliage in Quercus rubra (Zasada and Zahner 1969). In the present study, narrow vessels were lignified 2-8 weeks after full leaf expansion in flush-type species (Fig. 2I), as described by Zasada and Zahner (1969). In contrast, narrow vessels were also lignified between full leaf expansion and the end of elongation (Figs. 2I, 2J) or immediately after full expansion of successive leaves in intermediate-type species, consistent with the findings of Lodewick (1928) and Suzuki et al. (2000). Thus, lignification of narrow vessels might occur after full leaf expansion in flush-type species and around final leaf expansion in intermediate-type species.

\section{Leaf emergence pattern and vessel arrangement}

Ring- and diffuse-porous species do not have the same leaf emergence patterns, because these species show both flush- and intermediate-type leaf emergence patterns (Tables 1, 2). Ring-porous species can have abrupt or gradual transitions between pore- and non-pore zones (Woodcock 1989; Carlquist 2001). In the ring-porous species investigated in this study, we noted abrupt transitions in flush-type species and gradual transitions in intermediate-type species (Table 1, Fig. 1), although there was no relationship between leaf emergence pattern and vessel arrangement in diffuse-porous species (Table 1, Fig. 1).

Ladefoged (1952) and Denne (1976) described the relationships between vessel diameter and shoot elongation. Our findings suggest that these relationships apply to ring-porous species only, which form leaves and vessels synchronously. Thus the leaf emergence pattern might be predicted from the observations of vessel arrangement, and vice versa. 
Unlike other ring-porous species, $H$. tomentella showed late vessel formation. Kudo et al. (2014) experimentally showed that, at partially elevated temperatures of the stem, ring-porous species formed the first vessel elements (as well as a few narrow vessel elements) even in the absence of buds. Therefore, further studies are warranted to elucidate the cause and effect of leaf and vessel formation in connection with environmental factors. Systematic elucidation of the relationships between leaf phenology and vessel formation requires the analysis of additional species. Further, methods need to be developed for quantifying phenological characteristics of leaves and vessels at the whole-tree level and for observing seasonal changes in vessel formation on the trunk at a given location.

\section{Acknowledgments}

We thank the staff of the Ashiu Forest Research Station of the Field Science Education and Research Center, Kyoto University, for access to the tree specimens. We thank the Laboratory of Tree Cell Biology at the Graduate School of Agriculture, Kyoto University, for the use of a freezing microtome, and K. Takabe and A. Yoshinaga for help with the phloroglucinolhydrochloric acid reaction. Y. Onoda of the Laboratory of Forest Ecology, Graduate School of Agriculture, Kyoto University, provided advice on phylogenetic analyses. T. Niro assisted with sample collection and other students of the Laboratory of Forest Utilization, Graduate School of Agriculture, Kyoto University, provided assistance at various stages of the study. We also thank A. Osawa of this laboratory and E. Takahashi of the Laboratory of Faculty of Life and Environmental Science, Shimane University, for critical readings of the manuscript and for helpful suggestions. 


\section{References}

Atkinson, C.J., and Denne, M.P. 1988. Reactivation of vessel production in ash (Fraxinus excelsior L.) trees. Ann. Bot. 61(6): 679-688.

Begum, S., Nakaba, S., Yamagishi, Y., Oribe, Y., and Funada, R. 2013. Regulation of cambial activity in relation to environmental conditions: understanding the role of temperature in wood formation of trees. Physiol. Plant. 147(1): 46-54.

Carlquist, S. 2001. Comparative wood anatomy: systematic, ecological, and evolutionary aspects of dicotyledon wood. 2nd ed., completely revised. Springer-Verlag, New York.

Chaney, W.R., and Kozlowski, T.T. 1977. Patterns of water movement in intact and excised stems of Fraxinus americana and Acer saccharum seedlings. Ann. Bot. 41(6): 1093-1100.

Denne, M.P. 1976. Wood production and structure in relation to bud activity in some softwood and hardwood species. In Wood structure in biological and technological research. Edited by P. Baas, A.J. Bolton, D.M. Catling. Leiden Botanical Series, Leiden Univ. Press, Dordrecht, The Netherlands. pp. 204-211.

Digby, J., and Wareing, P.F. 1966. The relationship between endogenous hormone levels in the plant and seasonal aspects of cambial activity. Ann. Bot. 30(4): 607-622.

Ellmore, G.S., and Ewers, F.W. 1986. Fluid flow in the outermost xylem increment of a ring-porous tree, Ulmus americana. Am. J. Bot. 73(12): 1771-1774.

Ewers, F.W., and Fisher, J. B. 1989. Variation in vessel length and diameter in stems of six tropical and subtropical lianas. Am. J. Bot. 76(10): 1452-1459.

Fonti, P., Solomonoff, N., and García-González, I. 2007. Earlywood vessels of Castanea sativa record temperature before their formation. New Phytol. 173(3): 562-570.

Forest Research Station of Graduate School of Agriculture, Kyoto University. 2002. Meteorological observations in Kyoto University for No. 13, 1996-2000. (in Japanese.)

Fukushima, K., Funada, R., Sugiyama, J., Takabe, K., Umezawa, T., and Yamamoto, H. 2003. Secondary xylem formation-Introduction to biomass science. Kaiseisha Press. pp. 33-39. (in Japanese.) 
Greenidge, K.N.H. 1955. Studies in the physiology of forest trees. III. The effect of drastic interruption of conducting tissues on moisture movement. Am. J. Bot. 42(7): 582-587.

Hayashi, S. 1991. Micrographic atlas of Japanese woods. Wood Research Institute, Kyoto University. 23: 1-147. (in Japanese.)

Hayashi, Y., Furusato, K., and Nakamura, T. 1987. Illustrated trees in color. Hokuryukan, Japan. (in Japanese.)

Imagawa, H., and Ishida, S. 1972. Study on the wood formation in trees: report II. Development of the vessel in earlywood of hari-giri, Kalopanax pictus. Res. Bull. Coll. Exp. For. Hokkaido Univ. 29(1): 55-72. (in Japanese with English summary.)

Inoue, S., Utsumi, Y., Okano, T., Otsuki, K., Koga, S., Tashiro, N., and Nakai, T. 2002. Forests and trees of Kyushu University. Kyushu Univ. For. (in Japanese.)

Itoh, T. 1995. Anatomical description of Japanese hardwoods I. Reprinted from wood research and technical notes No. 31: 81-181. Wood Research Institute, Kyoto University, Uji, Kyoto, Japan. (in Japanese.)

Itoh, T. 1997. Anatomical description of Japanese hardwoods III. Reprinted from wood research and technical notes No.33: 83-201. Wood Research Institute, Kyoto University, Uji, Kyoto, Japan. (in Japanese.)

Kikuzawa, K. 1983. Leaf survival of woody plants in deciduous broad-leaved forests. 1. Tall trees. Can. J. Bot. 61(8): 2133-2139.

Kudo, K., Nabeshima, E., Begum, S., Yamagishi, Y., Nakaba, S., Oribe, Y., Yasue, K., and Funada, R. 2014. The effects of localized heating and disbudding on cambial reactivation and formation of earlywood vessels in seedlings of the deciduous ring-porous hardwood, Quercus serrata. Ann. Bot. 113(6): 1021-1027.

Ladefoged, K. 1952. The periodicity of wood formation. Dan. Biol. Skr. 7(3): 1-98.

Lechowicz, M.J. 1984. Why do temperate deciduous trees leaf out at different times? Adaptation and ecology of forest communities. Am. Nat. 124(6): 821-842.

Lodewick, J.E. 1928. Seasonal activity of the cambium in some northeastern trees. Bulletin of the New York State College of Forestry at Syracuse University Tech. Publ. 23: 1-87. 
Meyer, F.G., and Walker, E.H. 1984. Flora of Japan. Jisaburo Ohwi National Science Museum, Tokyo, Japan Smithsonian Inst. Washington, DC.

Miyazawa, Y., and Kikuzawa, K. 2004. Phenology and photosynthetic traits of short shoots and long shoots in Betula grossa. Tree Physiol. 24(6): 631-637.

Panchen, Z.A., Primack, R.B., Nordt, B., Ellwood, E.R., Stevens, A.-D., Renner, S.S., Willis, C.G., Fahey, R., Whittemore, A., Du, Y., and Davis, C.C. 2014. Leaf out times of temperate woody plants are related to phylogeny, deciduousness, growth habit and wood anatomy. New Phytol. 203(4): 1208-1219.

Sass, J.E. 1951. Botanical microtechnique, 2nd ed. The Iowa State College Press, USA, pp. 69-71.

Sass-Klaassen, U., Sabajo, C.R., and den Ouden, J. 2011. Vessel formation in relation to leaf phenology in pedunculate oak and European ash. Dendrochronologia 29(3): 171-175.

Suzuki, M., Yoda, K., and Suzuki, H. 1996. Phenological comparison of the onset of vessel formation between ring-porous and diffuse-porous deciduous trees in a Japanese temperate forest. IAWA 17(4): 431-444.

Suzuki, M., Hirano, R., and Yoda, K. 2000. Phenological analysis of wood formation in temperate deciduous ring and diffuse porous wood. Chonnam National Univ. Press, Kwangju, 2000. Printed in Korea, Reprint from Kim Y.S. (ed.) New Horizons in Wood Anatomy, pp. 132-137.

Takahashi, S., Okada, N., and Nobuchi, T. 2008. Examination of wood sampling method with an increment borer: An investigation of seasonal changes in vessel formation. For. Res., Kyoto 77(1-4): 123-128.

Takahashi, S., Okada, N., and Nobuchi, T. 2013. Relationship between the timing of vessel formation and leaf phenology in ten ring-porous and diffuse-porous deciduous tree species. Ecol. Res. 28(4): 615-624.

Tyree, M.T., and Zimmermann, M.H. 2002. Xylem structure and the ascent of sap, 2nd ed. Springer, Berlin, Heidelberg, New York. 
Umebayashi, T., Utsumi, Y., Koga, S., Inoue, S., Fujikawa, S., Arakawa, K., Matsumura, J., and Oda, K. 2008. Conducting pathways in north temperate deciduous broadleaved trees. IAWA 29(3): 247-263.

Utsumi, Y., Sano, Y., Fujikawa, S., Funada, R., and Ohtani, J. 1998. Visualization of cavitated vessels in winter and refilled vessels in spring in diffuse-porous trees by cryo-scanning electron microscopy. Plant Physiol. 117(4): 1463-1471.

Utsumi, Y., Sano, Y., Funada, R., Fujikawa, S., and Ohtani, J. 1999. The progression of cavitation in earlywood vessels of Fraxinus mandshurica var japonica during freezing and thawing. Plant Physiol. 121(3): 897-904.

Wakuta, R., Saiki, H., and Harada, H. 1973. Enlarging of differentiating vessel element in Firmiana platanifolia Shott et Endl. Bull. Kyoto Univ. For. 45: 204-216. (in Japanese with English abstract.)

Wheeler, E.A., Baas, P., and Gasson, P.E. 1989. IAWA list of microscopic features for hardwood identification with an appendix on non-anatomical information. IAWA Bull. n.s. 10(3): 219-332.

Woodcock, D.W. 1989. Distribution of vessel diameter in ring-porous trees. ALISO 12(2): 287-293.

Yagi, T. 2004. Within-tree variations in shoot differentiation patterns of 10 tall tree species in a Japanese cool-temperate forest. Can. J. Bot. 82(2): 228-243.

Zasada, J.C., and Zahner, R. 1969. Vessel element development in the earlywood of red oak (Quercus rubra). Can. J. Bot. 47(12): 1965-1971. 


\section{Table captions}

Table 1. Description of sample trees, including diameter at breast height, tree height, and number of trees during 2004 and 2005.

${ }^{a}$ Porosity classes were defined as in Hayashi 1991, except for Hovenia tomentella, which was determined by visual examination of pores.

${ }^{\mathrm{b}}$ Scientific names are based on those reported by Hayashi et al. (1987) except for Hovenia tomentella (Meyer and Walker 1984).

${ }^{c}$ The type of leaf emergence pattern of each species was determined by seasonal observation of tree specimens, and was based on the types reported by Kikuzawa (1983). In this study, flush and intermediate types were observed.

${ }^{\mathrm{d}}$ Branching of each species was determined by seasonal observation of tree specimens, and was based on the types reported by Kikuzawa (1983) and Yagi (2004).

e One Quercus mongolica var. grosseserrata tree had Japanese oak wilt disease in autumn 2005, although leaves and vessels continued to form until late summer.

${ }^{\mathrm{f}}$ One Castanea crenata tree had heartwood decay, but leaves and vessels continued to form in 2004.

${ }^{\mathrm{g}}$ No current-year vessels were observed in one Cercidiphyllum japonicum tree and one Fagus crenata tree in 2004, and in one Cercidiphyllum japonicum tree in 2005

Table 2 Porosity and leaf emergence patterns

Note: Scientific names are based on those reported by Kikuzawa (1983)

${ }^{a}$ Porosity classes for each species were assigned as defined by Hayashi (1991), Itoh (1995, 1997), and Inoue et al. (2002).

${ }^{\mathrm{b}}$ The type of leaf emergence pattern was reported for each species as defined by Kikuzawa (1983); flush and intermediate types were examined. 


\section{Figure captions}

Fig. 1 Photomicrograph of ring-porous species (upper) and diffuse-porous species (lower). Ring-porous species with flush-type leaf emergence pattern: Quercus mongolica var. grosseserrata and Zelkova serrata. Ring-porous species with intermediate-type leaf emergence pattern: Castanea crenata, Fraxinus mandshurica, and Hovenia tomentella. In ring-porous species, large black arrows point to wide vessels; large black arrowheads indicate medium-sized vessels; large white arrows point to narrow vessels. Diffuse-porous species with flush-type leaf emergence pattern: Aesculus turbinata and Fagus crenata. Diffuse-porous species with intermediate-type leaf emergence pattern: Betula grossa, Cercidiphyllum japonicum, and Pterocarya rhoifolia. In diffuse-porous species, small black arrows point to the first-formed vessels. White lines indicate ring borders

Fig. 2 Timing of vessel lignification relative to leaf phenology in ring-porous species in 2004 (upper) and 2005 (lower). (A) Timing of lignification of at least one wide vessel relative to the beginning of leaf appearance. (B) Timing of lignification of at least one wide vessel relative to completion of leaf appearance. (C) Timing of lignification of at least one wide vessel relative to full leaf expansion. (D) Timing of lignification of most wide vessels relative to full leaf expansion. (E) Timing of lignification of sparse wide vessels relative to full leaf expansion. (F) Timing of lignification of at least one medium-sized vessel relative to full leaf expansion. (G) Timing of lignification of most medium-sized vessels relative to the end of elongation. $(\mathrm{H})$ Timing of lignification of most medium-sized vessels relative to full leaf expansion of successive leaves. (I) Timing of lignification of narrow vessels relative to full leaf expansion. (J) Timing of lignification of narrow vessels relative to the end of elongation. Numbers in parentheses indicate the numbers of trees; circles indicate range; F, flush-type leaf emergence pattern; I, intermediate-type leaf emergence pattern; Qm, Quercus mongolica var. grosseserrata; Zs, Zelkova serrata; Cc, Castanea crenata; Fm, Fraxinus mandshurica; Ht, Hovenia tomentella.

Fig. 3 Timing of vessel lignification relative to leaf phenology in diffuse-porous species in 2004 (upper) and 2005 (lower). (A) Timing of lignification of the first-formed vessel relative to 
full leaf expansion. (B) Timing of lignification of the first-formed vessel relative to the end of elongation. Numbers in parentheses indicate the numbers of trees; circles indicate range; F, flush-type leaf emergence pattern; I, intermediate-type leaf emergence pattern; At, Aesculus turbinata; Fc, Fagus crenata; Bg, Betula grossa; $C j$, Cercidiphyllum japonicum; Pr, Pterocarya rhoifolia.

Takahashi et al. 20 
Table 1. Description of sample trees, including diameter at breast height, tree height, and number of trees during 2004 and 2005.

\begin{tabular}{|c|c|c|c|c|c|c|c|c|c|c|c|}
\hline \multirow[b]{2}{*}{ Porosity $^{a}$} & \multirow[b]{2}{*}{ Species $^{\mathrm{b}}$} & \multirow[b]{2}{*}{ Family } & \multirow[b]{2}{*}{$\begin{array}{l}\text { Leaf emergence } \\
\text { pattern }^{c}\end{array}$} & \multirow[b]{2}{*}{ Branching $^{\mathrm{d}}$} & \multirow[b]{2}{*}{$\begin{array}{l}\text { Transition between } \\
\text { pore- and non-pore } \\
\text { zone }\end{array}$} & \multicolumn{2}{|c|}{$\begin{array}{l}\text { Diameter at breast } \\
\text { height }(\mathrm{cm})\end{array}$} & \multicolumn{2}{|c|}{ Tree height $(\mathrm{m})$} & \multicolumn{2}{|c|}{$\begin{array}{l}\text { Number of trees } \\
\text { (trees) }\end{array}$} \\
\hline & & & & & & 2004 & 2005 & 2004 & 2005 & 2004 & 2005 \\
\hline \multirow[t]{5}{*}{$\begin{array}{l}\text { Ring- } \\
\text { porous }\end{array}$} & $\begin{array}{l}\text { Quercus mongolica Fisch. ex Ledeb. var. } \\
\text { grosseserrata (Blume) Rehder \& E.H.Wilson }\end{array}$ & Fagaceae & Flush & Monopodial & Abrupt & $28-47$ & $28-39$ & $13-22$ & $13-22$ & 5 & $4^{\mathrm{e}}$ \\
\hline & Zelkova serrata (Thunb.) Makino & Ulmaceae & Flush & Monopodial & Abrupt & $21-30$ & $21-30$ & $13-15$ & $13-15$ & 5 & 5 \\
\hline & Castanea crenata Siebold \& Zucc. & Fagaceae & Intermediate & Sympodial & Gradual & $18-59$ & $21-56$ & $12-21$ & $12-21$ & $5^{\mathrm{f}}$ & 5 \\
\hline & Fraxinus mandshurica Rupr. & Oleaceae & Intermediate & Monopodial & Gradual & $20-31$ & $20-31$ & $13-17$ & $13-17$ & 5 & 5 \\
\hline & Hovenia tomentella (Makino) Nakai & Rhamnaceae & Intermediate & Sympodial & Gradual & - & $18-38$ & - & $13-24$ & - & 5 \\
\hline \multirow{5}{*}{$\begin{array}{l}\text { Diffuse- } \\
\text { porous }\end{array}$} & Aesculus turbinata Blume & Hippocastanaceae & Flush & Monopodial & & $19-44$ & $19-44$ & $9-14$ & $9-14$ & 5 & 5 \\
\hline & Fagus crenata Blume & Fagaceae & Flush & Monopodial & & $41-50$ & $41-50$ & $14-21$ & $14-21$ & $5^{\mathrm{g}}$ & 5 \\
\hline & Betula grossa Siebold \& Zucc. & Betulaceae & Intermediate & Sympodial & & 20-34 & $20-34$ & $13-18$ & $13-18$ & 5 & 5 \\
\hline & Cercidiphyllum japonicum Siebold \& Zucc. & Cercidiphyllaceae & Intermediate & Sympodial & & $19-65$ & $19-74$ & $9-28$ & $9-31$ & $5^{\mathrm{g}}$ & $6^{\mathrm{g}}$ \\
\hline & Pterocarya rhoifolia Siebold \& Zucc. & Juglandaceae & Intermediate & Monopodial & & $23-34$ & $17-34$ & $17-20$ & $18-20$ & 5 & 5 \\
\hline
\end{tabular}

${ }^{a}$ Porosity classes were defined as in Hayashi (1991), except for Hovenia tomentella, which was determined by visual examination of pores.

${ }^{\mathrm{b}}$ Scientific names are based on those reported by Hayashi et al. (1987) except for Hovenia tomentella (Meyer and Walker 1984).

${ }^{c}$ The type of leaf emergence pattern of each species was determined by seasonal observation of tree specimens, and was based on the types reported by Kikuzawa (1983).

${ }^{\mathrm{d}}$ Branching of each species was determined by seasonal observation of tree specimens, and was based on the types reported by Kikuzawa (1983) and Yagi (2004).

'One Quercus mongolica var. grosseserrata tree had Japanese oak wilt in autumn 2005, although leaves and vessels continued to form until late summer.

${ }^{\mathrm{f}}$ One Castanea crenata tree had heartwood decay, but leaves and vessels continued to form in 2004

${ }^{\mathrm{g}}$ No current-year vessels were observed in one Cercidiphyllum japonicum tree and one Fagus crenata tree in 2004, and in one Cercidiphyllum japonicum tree in 2005 
Table 2. Porosity and leaf emergence patterns

\begin{tabular}{|c|c|c|}
\hline \multirow[b]{2}{*}{ Porosity ${ }^{a}$} & \multicolumn{2}{|l|}{ Leaf emergence pattern $^{\mathrm{b}}$} \\
\hline & Flush-type & Intermediate-type \\
\hline \multirow[t]{7}{*}{ Ring-porous } & Quercus mongolica var. grosseserrata & Picrasma quossioides \\
\hline & Maackia amurensis var. buergeri & Kalopanax pictus \\
\hline & & Fraxinus mandshurica var. japonica \\
\hline & & Ulmus davidiana var. japonica \\
\hline & & Ulmus laciniata \\
\hline & & Phellodendron amurense \\
\hline & & Castanea crenata \\
\hline \multirow[t]{16}{*}{ Diffuse-porous } & Fagus crenata & Betula platyphylla var. japonica \\
\hline & Prunus sargentii & Betula davurica \\
\hline & Prunus ssiori & Betula ermanii \\
\hline & Sorbus alnifolia & Betula maximowicziana \\
\hline & Acer mono & Cercidiphyllum japonicum \\
\hline & Aesculus turbinata & Cornus controversa \\
\hline & Carpinus cordata & Populus sieboldii \\
\hline & Acer palmatum var. matsumurae & Populus maximowiczii \\
\hline & Acer japonicum & Juglans ailanthifolia \\
\hline & Tilia japonica & Alnus japonica \\
\hline & Tilia maximowicziana & Magnolia obovata \\
\hline & Syringa reticulata & Sorbus commixta \\
\hline & Styrax obassia & Salix sachalinensis \\
\hline & & Salix hultenii var. angustifolia \\
\hline & & Salix subfragilis \\
\hline & & Ostrya japonica \\
\hline
\end{tabular}

Note: Scientific names are based on those reported by Kikuzawa (1983).

${ }^{a}$ Porosity classes for each species were assigned as defined in Hayashi (1991), Itoh (1995, 1997), and Inoue et al. (2002).

${ }^{\mathrm{b}}$ The type of leaf emergence pattern was reported for each species as defined by Kikuzawa (1983); flush and intermediate types were examined. 


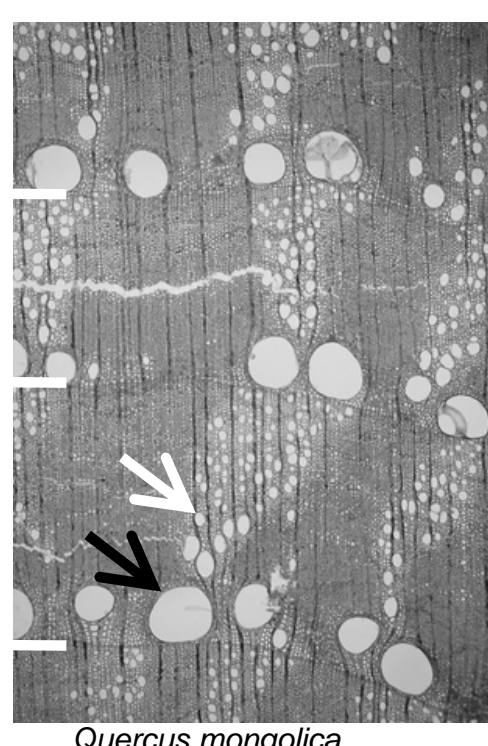

Quercus mongolica var. grosseserrata



Aesculus turbinata

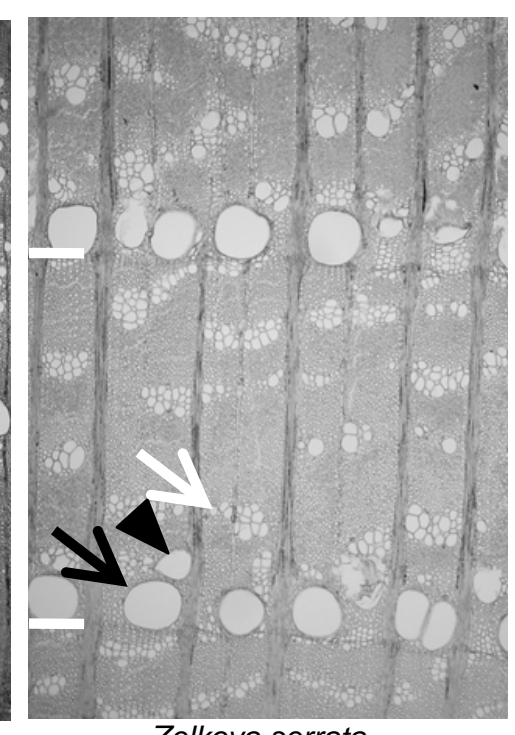

Zelkova serrata

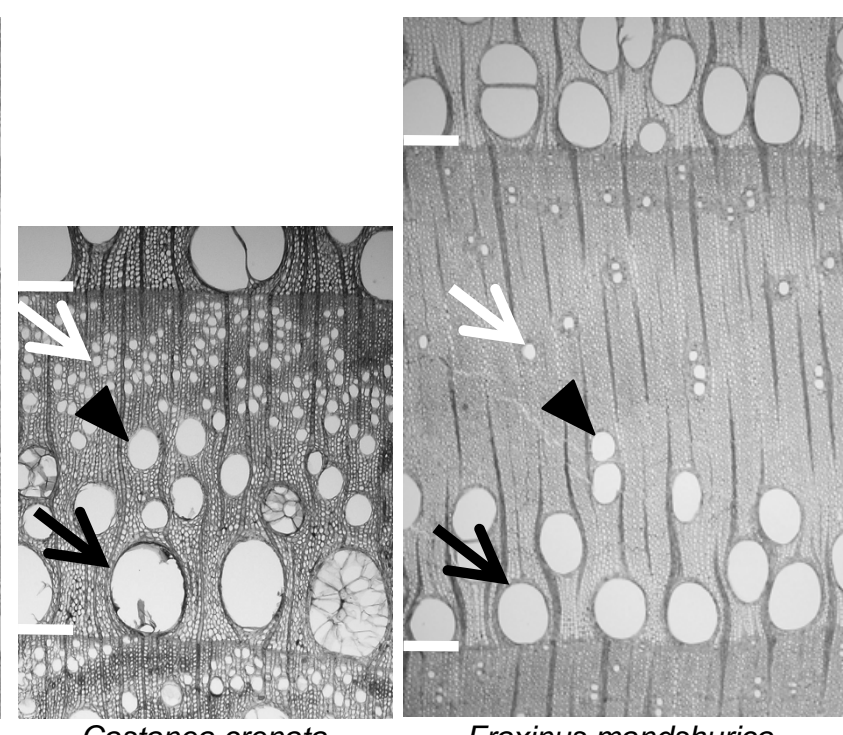

Castanea crenata

Fraxinus mandshurica

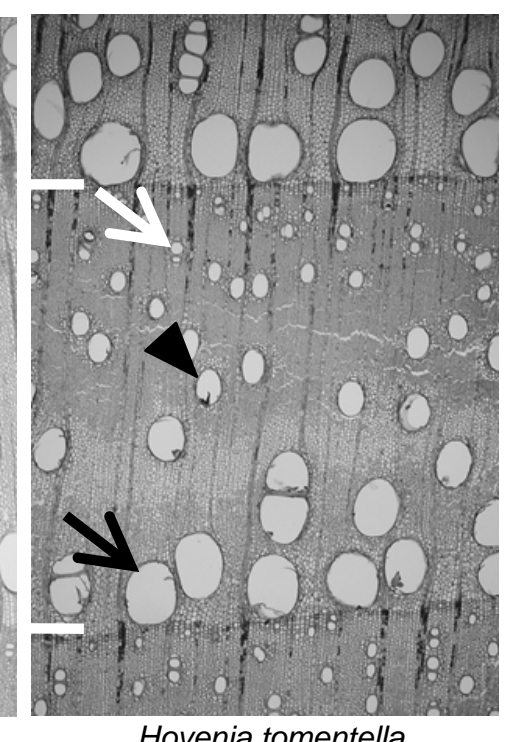

Hovenia tomentella

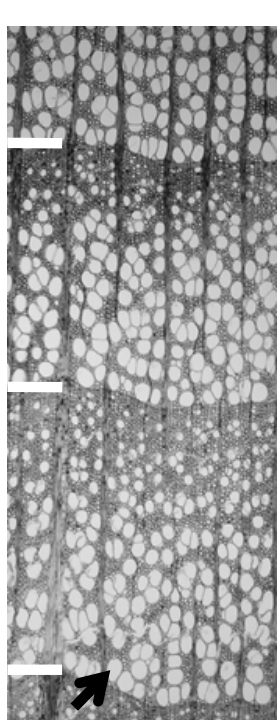

Fagus crenata

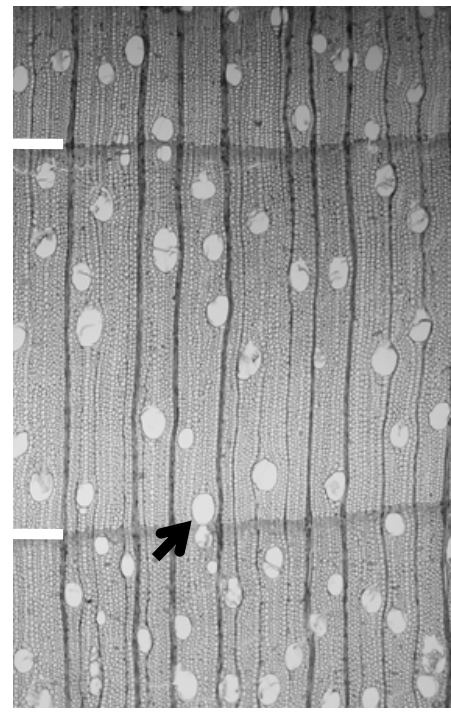

Betula grossa

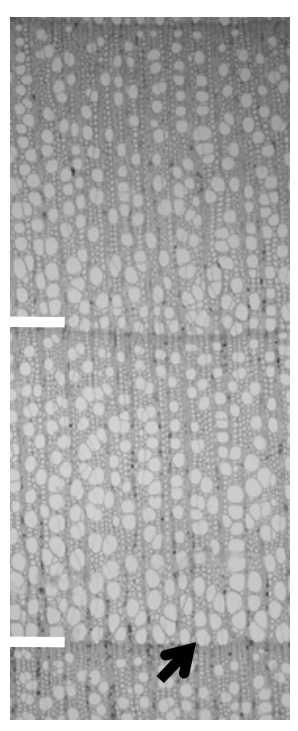

Cercidiphyllum

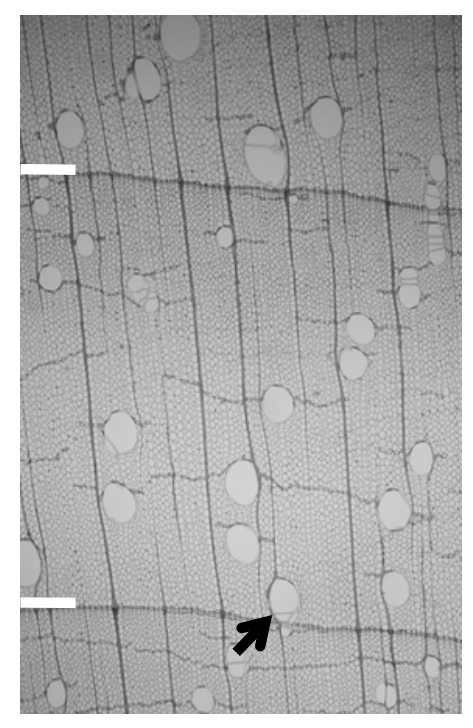

Pterocarya rhoifolia

$0 . \overline{\mathrm{mm}}$ japonicum

Fig. 1 Photomicrograph of ring-porous species (upper) and diffuse-porous species (lower). Ring-porous species with flush-type leaf emergence pattern: Quercus mongolica var. grosseserrata and Zelkova serrata. Ring-porous species with intermediate-type leaf emergence pattern: Castanea crenata, Fraxinus mandshurica, and Hovenia tomentella. In ringporous species, large black arrows point to wide vessels; large black arrowheads indicate medium-sized vessels; large white arrows point to narrow vessels. Diffuse-porous species with flush-type leaf emergence pattern: Aesculus turbinata and Fagus crenata. Diffuse-porous species with intermediate-type leaf emergence pattern: Betula grossa, Cercidiphyllum japonicum, and Pterocarya rhoifolia. In diffuse-porous species, small black arrows point to the first-formed vessels. White lines indicate ring borders 
(A)

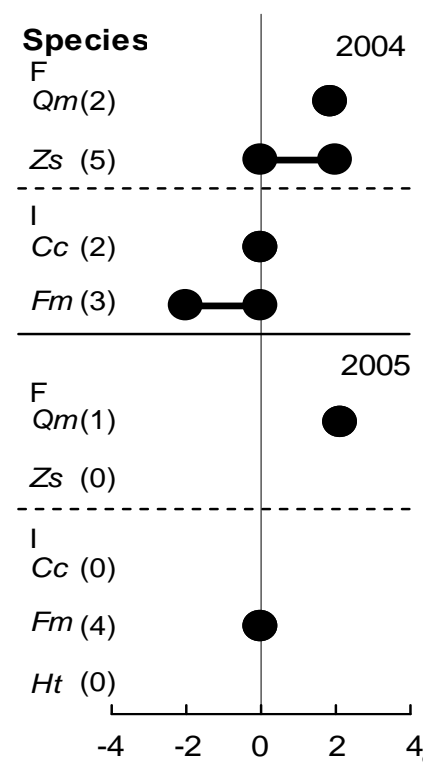

Time after the beginning of leaf appearance (weeks)

(C)

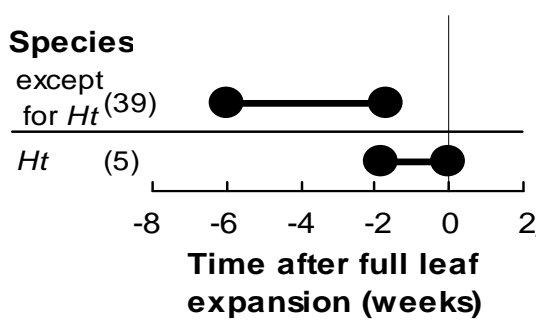

(B)

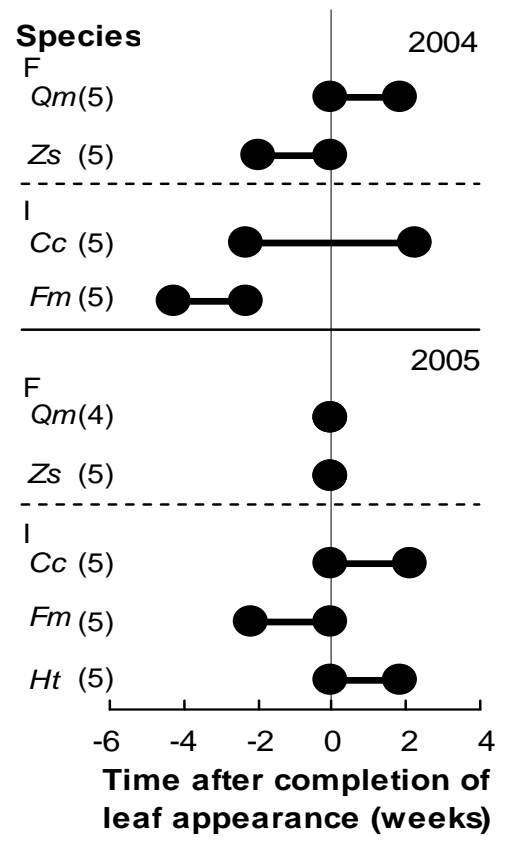

(D)



(E)

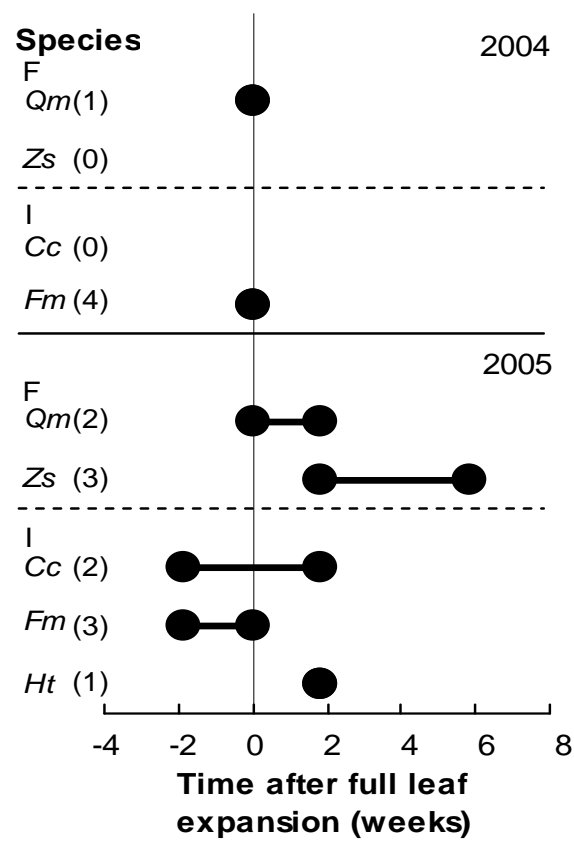

Fig. 2. Timing of vessel lignification relative to leaf phenology in ring-porous species in 2004 (upper) and 2005 (lower). (A) Timing of lignification of at least one wide vessel relative to the beginning of leaf appearance. (B) Timing of lignification of at least one wide ves sel relative to completion of leaf appearance. (C) Timing of lignification of at least one wide vessel relative to full leaf expansion. (D) Timing of lignification of most wide vessels relative to full leaf expansion. (E) Timing of lignification of sparse wide vessels relative to full leaf expansion. (F) Timing of lignification of at least one medium-sized vessel relative to full leaf expansion. (G) Timing of lignification of most medium-sized vessels relative to the end of elongation. $(\mathrm{H})$ Timing of lignification of most medium-sized ves sels relative to full leaf expansion of successive leaves. (I) Timing of lignification of narrow ves sels relative to full leaf expansion. (J) Timing of lignification of narrow vessels relative to the end of elongation. Numbers in parentheses indicate the numbers of trees; circles indicate range; F, flush-type leaf emergence pattern; I, intermediate-type leaf emergence pattern; Qm, Quercus mongolica var. grosseserrata; Zs, Zelkova serrata; Cc, Castanea crenata; Fm, Fraxinus mandshurica; Ht, Hovenia tomentella . 
(F)

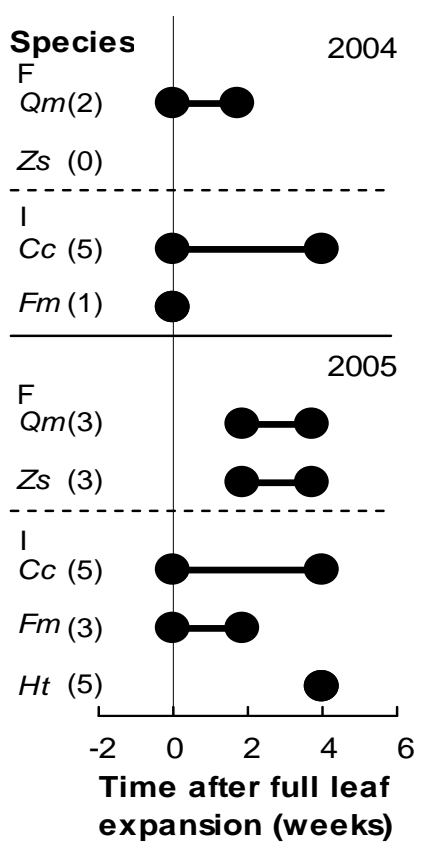

(G)

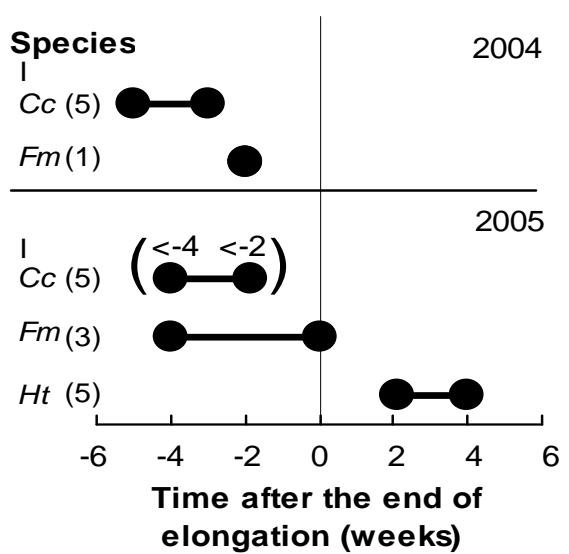

$(\mathrm{H})$

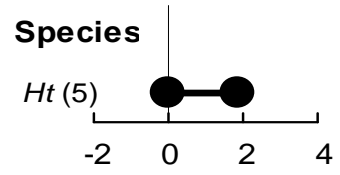

Time after full leaf expansion of successive leaves (weeks)
(I)

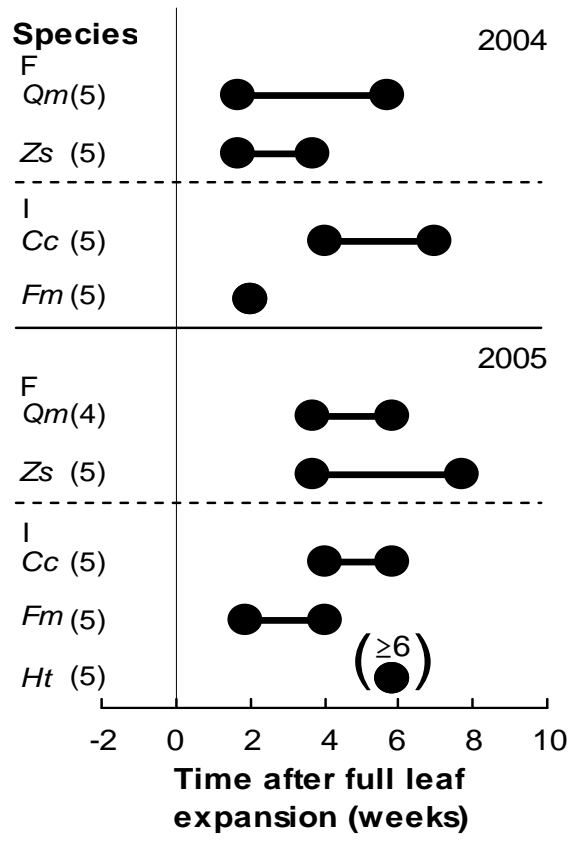

(J)

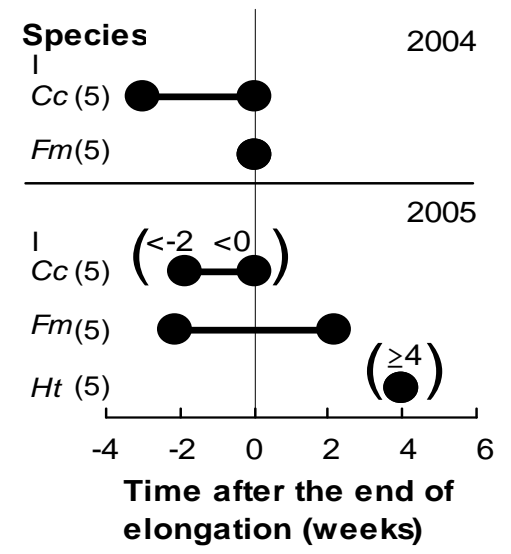

Fig. 2. (conduded) 
(A)

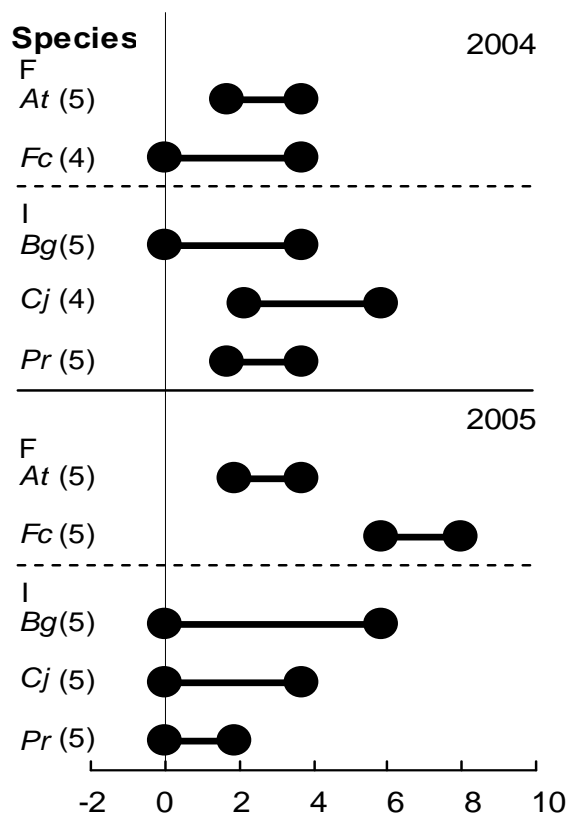

Time after full leaf expansion (weeks)
(B)

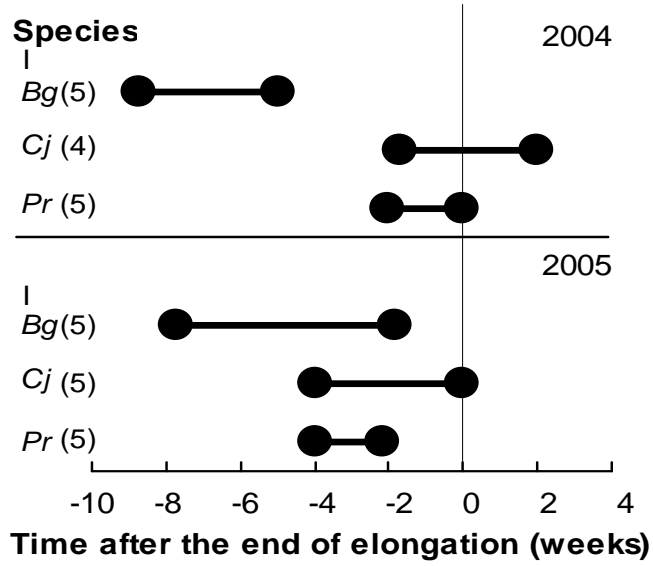

Fig. 3. Timing of vessel lignification relative to leaf phenology in diffuse-porous species in 2004 (upper) and 2005 (lower). (A) Timing of lignification of the first-formed vessel relative to full leaf expansion. (B) Timing of lignification of the firstformed vessel relative to the end of elongation. Numbers in parentheses indicate the numbers of trees; circles indicate range; F, flush-type leaf emergence pattern; I, intermediate-type leaf emergence pattern; At, Aesculus turbinata; Fc, Fagus crenata; Bg, Betula grossa; $\mathrm{Cj}$, Cercidiphyllum japonicum; Pr, Pterocarya rhoifolia . 


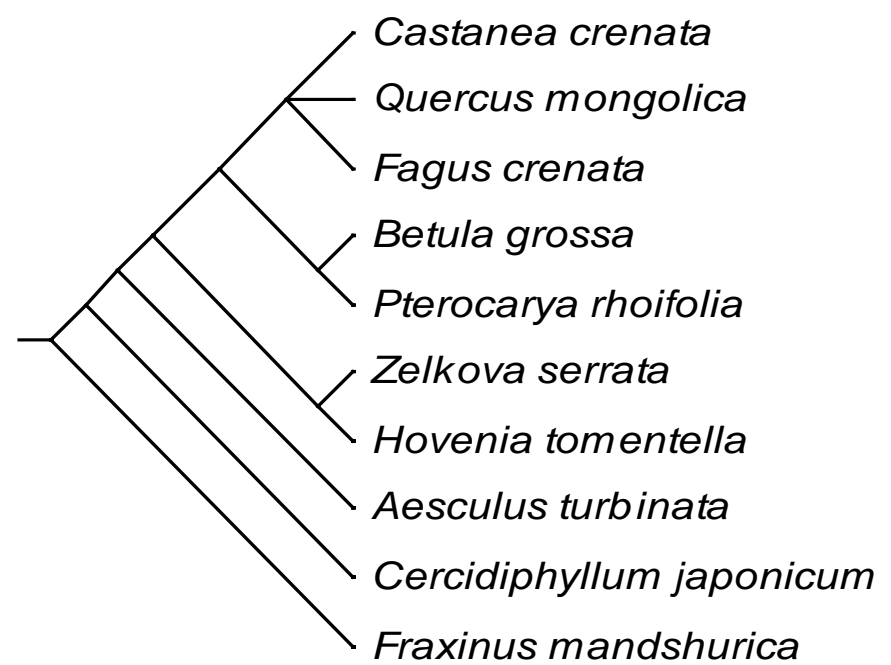

Supplementary Fig. S1. Phylogenetic tree of sample species (from C.O. Webb and M. Donoghue. 2005. Phylomatic: a database for applied phylogenetics. Available from http://www.phylodiversity.net/phylomatic, last accessed 21 October 2014). 